\title{
A COVID-19 E SEU IMPACTO NO CAMPO MUSICAL EM MANAUS: RELAÇÕES DE PODER, RESISTÊNCIAS E RE-EXISTÊNCIAS
}

\author{
COVID-19 and its impact on the musical field in Manaus: \\ power relations, resistances and re-existences \\ COVID-19 y su impacto en el campo musical de Manaus: \\ relaciones de poder, resistencias y re-existencias
}

Klissy Kely Guimarães ${ }^{1}$

\begin{abstract}
Resumo:
Discorrer a respeito das relações humanas que transcorrem no campo musical em Manaus, ainda mais após o impacto da pandemia causada pelo novo coronavírus, revela-se como uma demanda urgente. Este estudo se propõe à reflexão das fragilidades do trabalho musical/artístico, nas implicações do isolamento social e da drástica queda de renda financeira nas existências dos profissionais da música na cidade, uma vez que apresentações presenciais foram paralisadas. Por meio de análise dialógica de conteúdos jornalísticos que tratam deste tema e de autores da antropologia e sociologia, busca-se um entendimento do alcance das políticas públicas impostas pelas instâncias de poder nesta área e dos seus impactos sociais e econômicos no referido campo.
\end{abstract}

Palavras-chave: Campo musical; Covid-19 em Manaus; Relações de poder; Música.

\begin{abstract}
:
Discussing the human relationships that take place in the musical field in Manaus, especially after the impact of the pandemic caused by the new coronavirus, reveals itself as an urgent demand. This study proposes to reflect on the weaknesses of musical / artistic work, on the implications of social isolation and the drastic drop in financial income in the existence of music professionals in the city, since in-person presentations were halted. Through a dialogical analysis of journalistic contents that deal with this theme and authors of anthropology and sociology, we seek an understanding of the scope of public policies imposed by the authorities in this area and their social and economic impacts in that field.
\end{abstract}

Keywords: Musical field; Covid-19 in Manaus; Power relations; Music

\footnotetext{
${ }^{1}$ Musicista, compositora e Mestra em Ciências Humanas - (História, teoria e crítica da cultura) pelo do Programa de Pós-graduação Interdisciplinar em Ciências Humanas - PPGICH da Universidade do Estado do Amazonas - UEA. E-mail: klissykely@gmail.com.
} 


\section{Resumen}

Hablar de las relaciones humanas que se desarrollan en el ámbito musical en Manaus, más aún después del impacto de la pandemia provocada por el nuevo coronavirus, se revela como una demanda urgente. Este estudio propone reflexionar sobre las debilidades del trabajo musical / artístico, sobre las implicaciones del aislamiento social y la drástica caída de los ingresos económicos en la existencia de profesionales de la música en la ciudad, ya que las presentaciones presenciales quedaron paralizadas. A través de un análisis dialógico de los contenidos periodísticos que abordan esta temática y autores de la antropología y la sociología, buscamos comprender el alcance de las políticas públicas impuestas por las autoridades en esta área y sus impactos sociales y económicos en ese campo.

Palabras clave: Campo musical; COVID-19 en Manaos; Relaciones de poder; Música

\section{Introdução}

Este artigo se propõe à reflexão dos impactos da pandemia do novo coronavírus SARS-CoV-2 (COVID-19) no campo musical em Manaus na busca por um entendimento crítico das relações de poder com implicações nas existências dos profissionais da área. Vale considerar que a concepção de Campo Musical aqui presente parte do conceito de campo apresentado por Pierre Bourdieu (2007). Será exposto um breve histórico da chegada da doença na cidade e das primeiras medidas sanitárias tomadas pelas instâncias de poder para barrar a sua disseminação. Discorrer-se-á também sobre aspectos referentes às fragilidades intrínsecas do trabalho com a música, bem como reinvenções e adaptações pelas quais artistas, músicos e profissionais da área em geral, tiveram que realizar para poderem exercer suas atividades musicais de modo seguro e ter ao menos fonte de renda mínima na viabilização de suas subsistências.

Abordar-se-á, a partir de uma perspectiva sócio antropológica, as questões que envolvem as relações de poder, no que concerne aos impactos sociais e econômicos das medidas e políticas adotadas pelas instâncias em questão, discorrendo ainda sobre o alcance delas na realidade dos profissionais atuantes no referido campo. Para tanto, este artigo se propõe a refletir a respeito dos reflexos da pandemia já sentidos, a mudança social causada por ela até então e sobre a importância da arte para as pessoas, na tentativa de dar sentido e alimentar não só o corpo, mas também o espírito.

\section{A chegada da pandemia em Manaus}

O primeiro caso confirmado do novo coronavírus (COVID-19) na cidade de Manaus ocorreu em 13 de março de 2020. Desde então uma série de mudanças drásticas em várias esferas da sociedade têm impactado as pessoas e os hábitos sociais de diferentes formas. Neste contexto, o campo musical manauara, como outros campos, sofreu e teve que se readequar de modo repentino às novas normas do poder públi$\mathrm{Co}^{2}$ e recomendações da Organização Mundial da Saúde (OMS) assim como em várias partes do planeta.

Em meio às questões burocráticas em adaptação diante de uma nova realidade, acontecimentos que atingem as subsistências têm sido mais fortemente sentidos nas periferias, explicitando a negligência e despreparo do Estado e do poder público como um todo. A desigualdade social e falta de estrutura na cidade que tem população estimada de $2.219 .580^{3}$ conforme dados do Instituto Brasileiro de Geografia e Estatística (IBGE, 2018) e possui o $8^{\circ}$ maior PIB do país, tem se acentuado neste contexto pandêmico.

\footnotetext{
${ }^{2}$ A exemplo da Lei 13.979 disponível em <http://www.fvs.am.gov.br/media/doctos/LEl_13.979.pdf>. Acesso em 13/10/2020

${ }^{3}$ Dados informados pelo Censo Instituto Brasileiro de Geografia e Estatística - IBGE de 2018 disponíveis pelo link <https://cidades.ibge.gov.br/brasil/am/manaus/panorama>. Acesso em 23/09/2020.
} 
Neste sentido, é válido o debate a respeito do modo como as políticas públicas para conter o avanço da doença têm sido implementadas na capital amazonense, buscando evitar o colapso dos hospitais e do sistema de saúde como um todo na cidade e suas prováveis falhas. "O que é governar? Governar segundo o princípio da razão de Estado é fazer que o Estado possa se tornar sólido e permanente, que possa se tornar rico, que possa se tornar forte diante de tudo o que pode destruí-lo", segundo Michel Foucault (2008: p. 6). Esse tem se mostrado um enorme desafio do poder público no contexto pandêmico, que no âmbito estadual foram agravadas por suspeitas de desvio de verba da saúde em meio ao desenrolar de uma Comissão Parlamentar de Inquérito (CPI $)^{4}$.

Até o dia 08/04/2020 era na capital que se concentravam o maior número de casos do novo coronavírus no Amazonas. A capital manauara tinha até então registrado 88\% dos casos confirmados de COVID-19. "[...] em Manaus foram registrados 712 casos, e em 14 municípios do interior o total é de 92 casos." (LEVENTI, 2020, p.1). Ressalta-se que estes dados correspondem ao início da ascensão da curva de crescimento da pandemia na cidade. Ao compará-lo com as informações do boletim de no 186 do dia 05/10/2020 pela Fundação de Vigilância e Saúde do Amazonas - FVS/AM ${ }^{5}$ a partir dos dados enviados pelas secretarias municipais de saúde pelos sistemas e-SUS Notifica, Sistema de Informação da Vigilância Epidemiológica da Gripe (Sivep-Gripe) e o Gerenciador de Ambiente Laboratorial (GAL) em pouco mais de seis meses após o primeiro caso apresentado, nota-se que:

Em Manaus, foram notificados 159.931 casos, enquanto no interior do estado, o número chega a 192.420 [...] Dos 142.573 casos confirmados no Amazonas até esta segunda-feira (05/10), 53.371 são de Manaus (37,43\%) e 89.202 do interior do estado (62,57\%) [...] Entre pacientes em Manaus, há o registro de 2.649 óbitos confirmados em decorrência do novo coronavírus. No interior, são 61 municípios com óbitos confirmados até o momento, totalizando 1.536. (grifo nosso). (Portal FVS/AM, 2020)..

Atendendo às recomendações das autoridades de saúde nacionais e internacionais, para a contenção do novo coronavírus, as primeiras medidas tomadas pelo Governo do Amazonas por meio da então Secretaria Estadual de Saúde (SUSAM) ${ }^{6}$, foi a criação do Plano de Contingência para Infecção Humana pelo COVID-19 com ações planejadas no âmbito do Comitê Interinstitucional de Gestão de Emergência em Saúde Pública visando respostas rápidas aos vírus respiratórios, com ênfase no COVID-19 e outros vírus domésticos causadores de síndromes respiratórias graves. Todavia deve-se considerar que as medidas adotadas pelo poder público não foram suficientes para conter o avanço da doença muito menos impedir sua disseminação no estado, evidenciando as falhas na execução das políticas para sua contenção, agravadas por uma desobediência sanitária de parte considerável da população fundada em fake news.

No balanço divulgado dia 20/04/2020 dos 2.160 casos confirmados no Amazonas 1.772 eram de Manaus e 388 do interior do estado (Portal FVS, 2020), isso corresponde ao momento em que a capital do Amazonas ainda não havia atingido o pico de crescimento da doença. Naquele contexto, na esfera estadual e municipal foram adotadas medidas de distanciamento físico, não obrigatório, excetuando apenas os serviços essenciais como limpeza pública, saúde, segurança e transporte público. Tais dados comparados

\footnotetext{
${ }^{4}$ Informações obtidas por meio do link <https://d24am.com/politica/operacao-da-pf-atinge-governo-wilson-lima/>. Acesso em 13/10/2020.

${ }^{5}$ Informações obtidas por meio do link<http://www.fvs.am.gov.br/noticias_view/4196>. Acesso em 05/10/2020

${ }^{6}$ A nomenclatura SUSAM foi substituída por Sistema de Estado da Saúde (SES-AM) pelo governo do Amazonas desde agosto de 2020.
} 


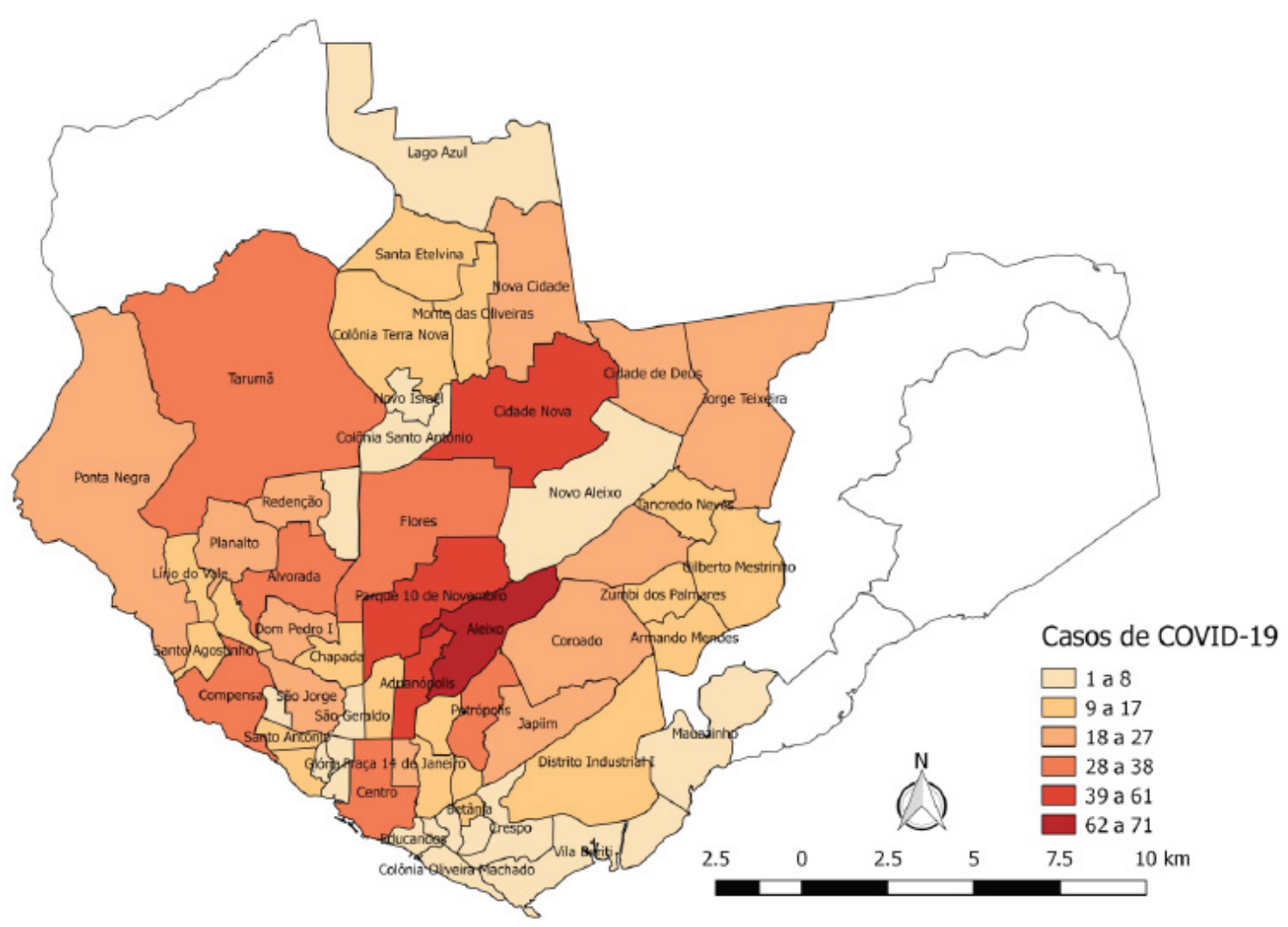

Figura 1 - Casos do novo coronavírus por bairros de Manaus. Fonte: FVS. Dados atualizados até 16/04/2020

ao mapeamento monitorado de seis meses depois permitem visualizar o impacto da pandemia na cidade e onde se situam as maiores incidências por bairros.

Os artistas que, em grande parte são profissionais autônomos, e mais especificamente os da música, ganham de acordo com o número de apresentações que fazem por dia ou semana, não possuindo, em sua maioria, carteira assinada ou plano de saúde, sendo, portanto, dependentes do Sistema Único de Saúde (SUS). Por conta das novas normas, como a cidade teve suas atividades não essenciais canceladas e/ ou paralisadas, tais artistas se viram num dilema, se de um lado teria o risco à saúde coletiva, à sua própria e de seus familiares, do outro, estaria a preocupação em se manter, se alimentar e pagar as contas.

\section{Impactos das medidas sanitárias no Campo Musical}

O fazer musical de modo geral é algo complexo e se estende a diversos outros campos da vida social. Qualquer mudança social por mínima que seja causa reflexos não só no exercício desse trabalho, mas também nas produções musicais de um determinado espaço, por estarem intimamente relacionadas com as pessoas ali alocadas provocando-lhes as mais diversas reações. No entanto, deve-se ressaltar conforme John Blacking (2007) que "a música não é apenas reflexiva, mas também gerativa, tanto como sistema cultural quanto como capacidade humana" (p. 201).

A partir das primeiras medidas de isolamento social na segunda quinzena de março de 2020, a classe artística dentro do campo musical em Manaus criou fóruns e grupos de discussão em redes sociais em busca de alternativas de subsistência, dentre elas pode-se destacar o Mobiliza Cultura $\mathrm{AM}^{7}$ onde artistas de diferentes segmentos, jornalistas e profissionais da cultura têm, desde as primeiras paralizações, compartilhado suas

\footnotetext{
${ }^{7}$ Grupo criado em rede social para tratar de questões emergenciais em prol da classe artística manauara.
} 


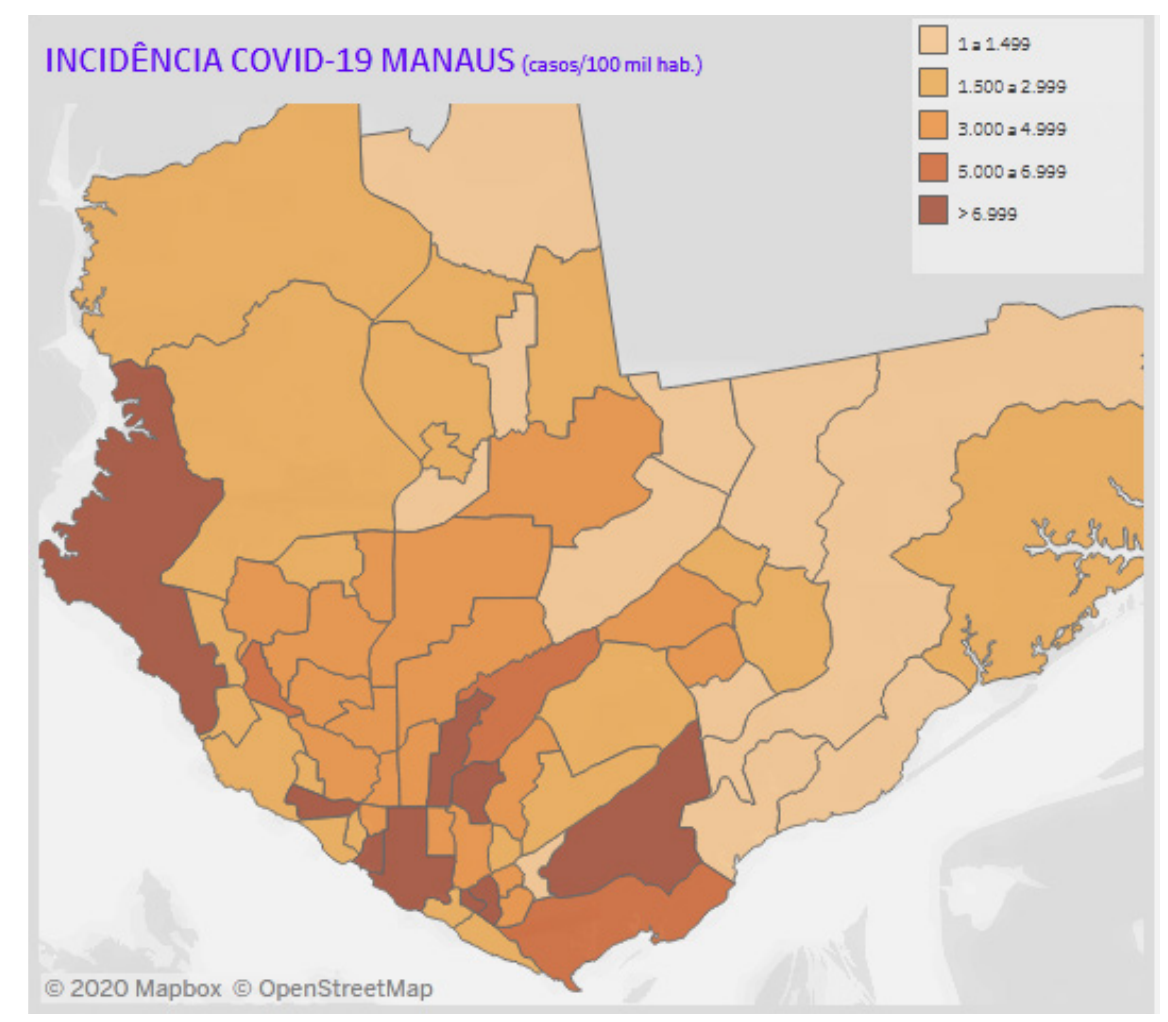

Figura 2 - Casos do novo coronavírus por bairros de Manaus. Fonte: FVS. Dados atualizados até 16/10/2020 ${ }^{8}$

experiências, suas necessidades mais urgentes e promovido debates e reuniões com os órgãos e secretarias de cultura tanto da esfera municipal como da estadual e exigindo por meio de carta aberta ${ }^{9}$ respostas rápidas destes para a viabilização de ações emergenciais e políticas públicas de curto prazo para artistas que sofreram perdas significativas em razão de cancelamentos de seus eventos (BORGES, Portal Amazônia, 2020).

De acordo com o levantamento realizado pela Secretaria de Cultura e Economia Criativa do Estado do Amazonas - SEC/AM, pouco mais de quatro mil profissionais da cultura foram afetados negativamente pela pandemia do novo coronavírus no estado.

Mais de 50\% dos cadastrados responderam que atuam há mais de 10 anos em suas respectivas áreas, e a maioria realizava atividades culturais três ou mais vezes por semana. Mais de 60\% dos participantes também informou renda familiar mensal de até um salário mínimo. (Portal SEC, ${ }^{10} 2020$ ).

Além da paralização de shows musicais, para os artistas de modo geral, produzir música em Manaus no contexto pandêmico se tornou um desafio ainda maior, visto a impossibilidade de realizar ensaios ou gravações dentro dos moldes já conhecidos. Seria necessária uma reinvenção do modo de produção musical e do fazer musical em si. Neste sentido a tecnologia, por meio de aplicativos, redes sociais dentre outros aparatos, veio ao encontro da necessidade de adaptação de diversos artistas, músicos e profissionais

\footnotetext{
${ }^{8}$ Dados obtidos a partir do monitoramento da FVS disponível em <http://www.fvs.am.gov.br/indicadorSalaSituacao_ view/60/2>. Acesso em 16/10/2020.

${ }^{9}$ Link onde consta a carta aberta <https://bit.ly/AssineACartadoMobilizaCultura> de 26/03/2020. Acesso em 10/04/2020.

${ }^{10}$ Dados obtidos pelo link < https://cultura.am.gov.br/portal/mais-de-4-mil-artistas-e-profissionais-se-cadastram-em-mapeamento-do-governo-do-amazonas/> Acesso em 06/10/2020
} 
em geral, aumentando assim produções do tipo $L o-f^{11}$. Todavia, até que isso fosse possível seria fundamental acalmar os ânimos e pensar em alternativas de viabilizar e se manter no trabalho com a música.

Apesar da música, assim como a arte em geral, ser algo construído, provocado por uma gama de acontecimentos antecedentes e conhecimentos prévios advindos do contexto que envolve o artista, ela é experienciada como algo imanente. De todo modo, o fato do processo elaborativo musical ser vivido de um modo diferente do que ele de fato é, não implica exatamente numa falsa consciência de seu próprio trabalho. A música enquanto objeto de arte seria então um produto das relações sociais.

Para Bourdieu (2007, p.162), o espaço social engendra o campo, e ele, por sua vez estrutura e também é estruturado pelos agentes sociais nele inseridos. As questões pertinentes ao espaço social seriam formuladas nesse mesmo espaço pelos próprios agentes cujos pontos de vistas dependem da posição que ocupam e seriam fatores provocativos da vontade de transformar ou conservar tal espaço (ibidem, p.162). Todavia, deve-se ter cautela na apresentação das questões que envolvem a vida social, segundo Cavalcanti (2012, p.45) "a realidade não pode ser reduzida a explicação ingênua de um fenômeno e a sua submissão direta às determinações econômicas e sociais". As relações sociais no referido contexto pandêmico sofrem tensões mais ou menos acentuadas devido às incertezas na esfera da vida humana, com implicações na existência e na subsistência das pessoas.

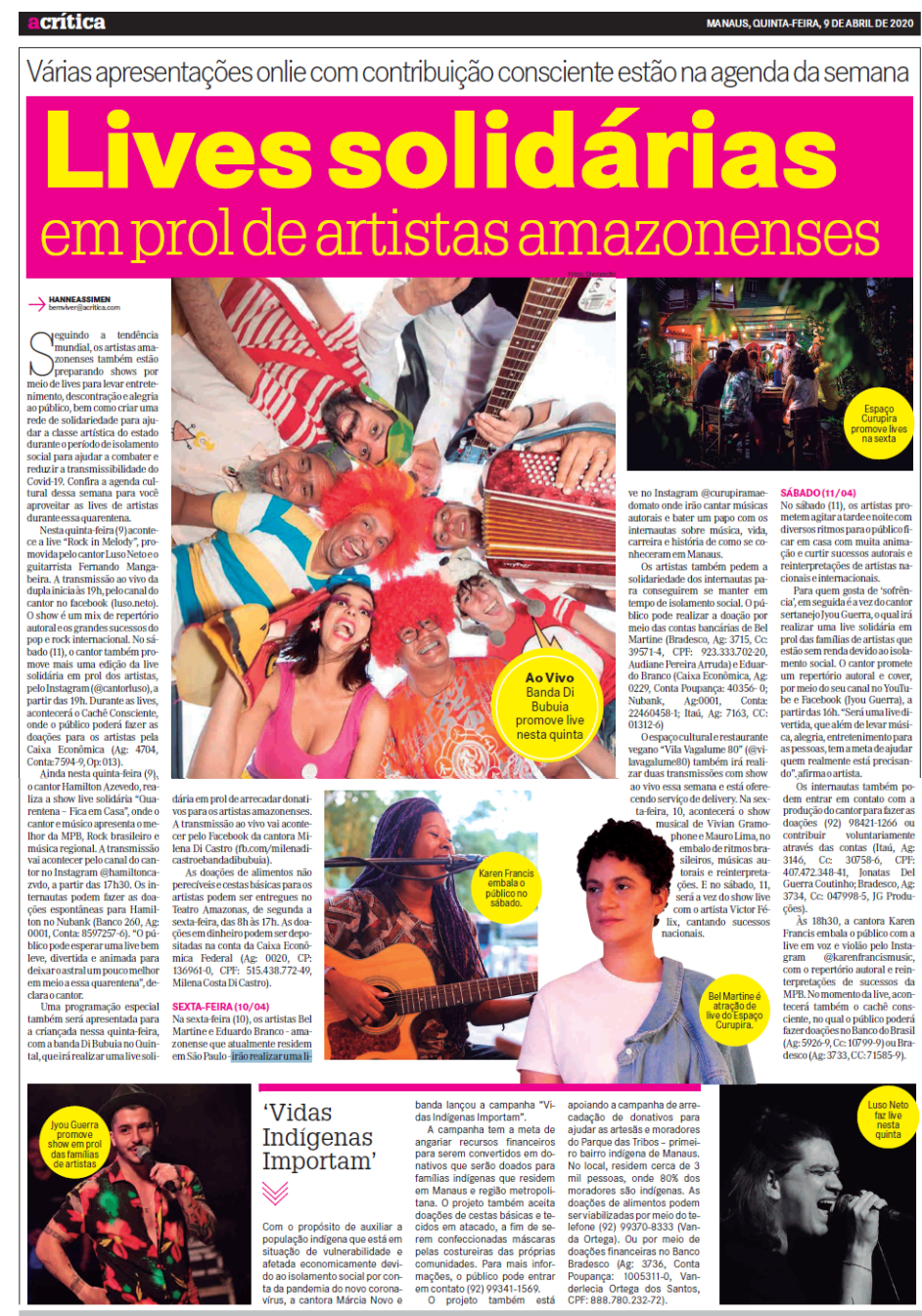

Figura 3 - Fonte: Jornal A crítica. Caderno: Bem viver. ASSIMEN, Hanne. Título: “Lives solidárias são realizadas em prol de artistas amazonenses". Data: 08 de abril de 2020. Acesso em 10/04/2020.

\footnotetext{
${ }^{11}$ Produções musicais de baixo custo.
} 
Isto posto, seguindo uma tendência mundial, dentre as propostas e alternativas mais difundidas e de rápido retorno financeiro dentro do referido campo diante da nova realidade imposta pela pandemia estão as "Lives Solidárias", que são shows virtuais feitos com ou sem grandes estruturas pelos artistas e músicos em suas respectivas casas ou espaços culturais sem a presença de público.

Os telespectadores que compõem o público poderiam depositar uma quantia na conta do artista, previamente informada nos cartazes de divulgação, depois de assistirem as apresentações pela Internet via redes sociais. Neste sentido, as lives das mais diversas formas, intuitos e conteúdos foram realizadas pelos artistas locais e profissionais da área no decorrer do período de isolamento social imposto pelas instâncias de poder a fim de atenuar a transmissibilidade da Covid-19 em Manaus. O que movimentou bastante as redes sociais, que passaram a exercer então, ao longo desse tempo, o papel de principal espaço para discussões, divulgações e palcos dos eventos virtuais e/ou on line.

As chamadas "vakinhas virtuais" também foram um alternativa de subsistência encontrada por grupos de artistas para se manterem durante o período de isolamento. Além disso, a pandemia que se impôs obrigou os profissionais da música e da cultura como um todo, a repensar e/ou adiar suas estratégias, planejamentos e projetos previstos para o ano de 2020. Os artistas e profissionais da música atuantes no referido campo se viram diante de demandas inéditas, conforme ilustra a matéria jornalística a seguir. As chamadas "vakinhas virtuais" também foram um alternativa de subsistência

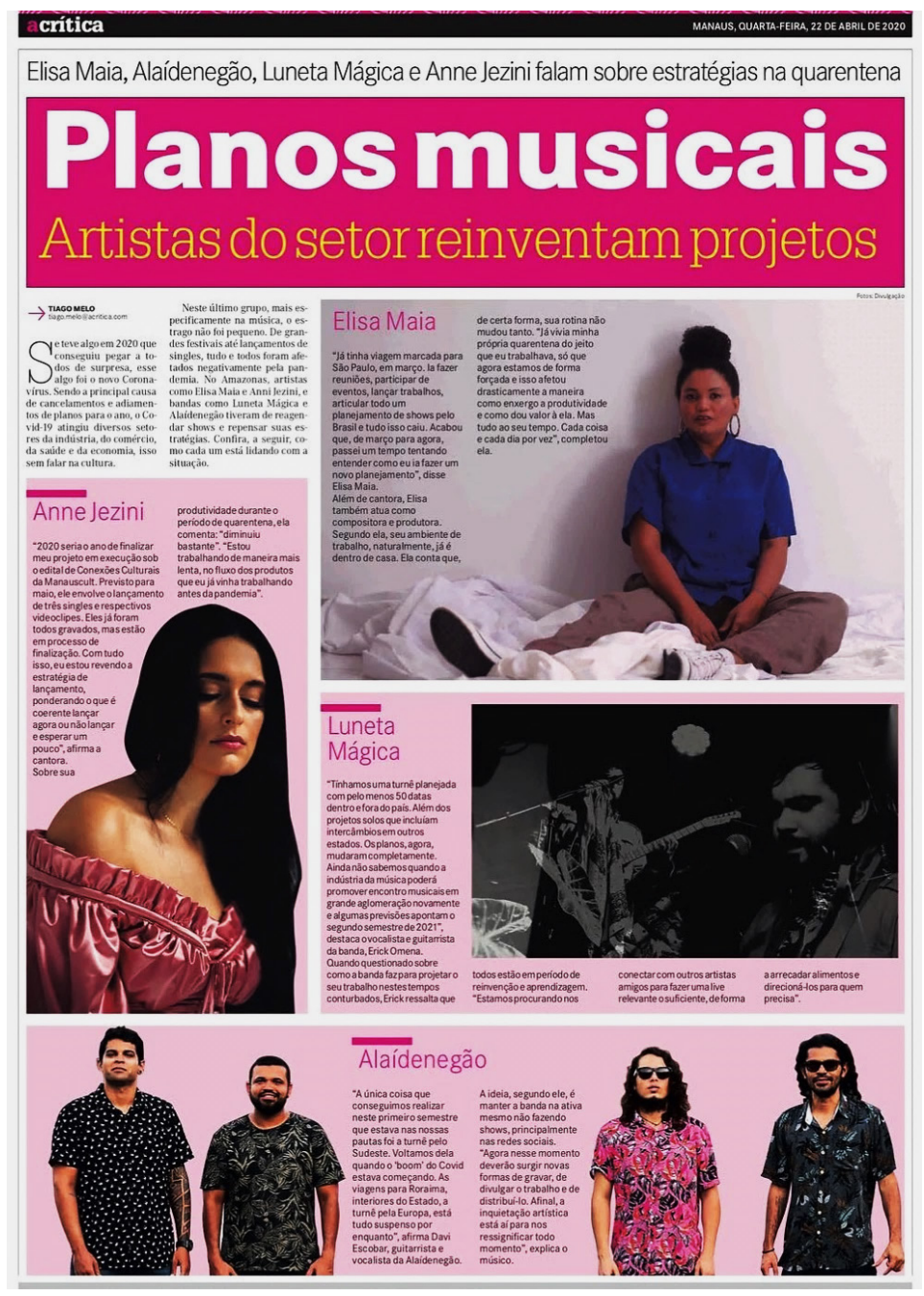

Figura 4 - Fonte: Jornal A crítica. Caderno: Bem viver. MELO, Tiago. Título: “Planos musicais: artistas do setor reinventam projetos". Data: 22 de abril de 2020. Acesso em 04/10/2020. 
Neste sentido, os subsídios proporcionados por editais de cultura tiveram uma busca significativa neste período, entretanto, a burocracia exigida para viabilizar projetos evidenciou em certos casos a falta de sensibilidade, organização e proatividade das instâncias de poder que tratam das questões culturais na cidade ante a uma situação sem precedentes. Deve-se considerar que burocracia não pode ser tida como sinônimo de transparência no tratamento com o dinheiro público. Os mecanismos de transparência podem corresponder a uma prática menos obstaculizante diante de uma mudança social imposta, sem prejuízos éticos e/ou morais para a gerência e finanças públicas.

Em relação às respostas dos órgãos de cultura na esfera municipal, a Fundação Municipal de Cultura e Arte - MANAUSCULT, não se pronunciou, nem propôs medidas próprias de ajuda emergencial para os artistas atuantes na cidade restringindo-se ao prosseguimento de editais de prêmios anteriores e a aplicação do que lhe cabe da Lei n ${ }^{\circ}$ 14.017, de 29 de junho de 2020, denominada de Lei Aldir Blanc ${ }^{12}$. A Secretaria de Estado da Cultura e Economia Criativa - SEC/AM ainda no mesmo mês dos primeiros casos da pandemia divulgou a proposta Cultura sem sair de Casa que consistia em disponibilizar acervos digitais dos eventos viabilizados por ela para o público e se propôs ao diálogo considerando as demandas apresentadas pela classe artísticas encabeçadas pelo Mobiliza Cultura AM apresentando então o Edital Público de Seleção de Propostas para Realização de Atividades Artísticas de Conteúdo Virtual (Edital nº4/2020) conhecido como Fica na rede maninho.

\section{Relações de poder}

As políticas públicas emergenciais são medidas paliativas para atenuar os impactos negativos gerados pelos cancelamentos, adiamentos involuntários e paralizações de uma gama de eventos e apresentações artísticas/ musicais/ culturais em todo o país. Na esfera federal, a denominada Lei Aldir Blanc dispõe a respeito da garantia da renda emergencial para trabalhadores da cultura e da manutenção dos espaços e equipamentos culturais brasileiros durante o período de pandemia de COVID-19 respeitando as devidas especificações, semelhante ao que dispõe o Decreto Legislativo $\mathrm{n}^{\circ}$ 6, de 20 de março de 2020 conhecido como auxílio emergencial. Ficando a cargo das secretarias municipais e estaduais a organização e remanejamento do auxílio financeiro proposto pela lei.

Deve-se frisar que a referida lei foi uma conquista da pressão da classe artística brasileira que apresentou tal demanda ao poder legislativo por meio de abaixo assinados e petições. Outras instituições também tomaram medidas emergenciais e elaboraram editais neste sentido, uma vez reconhecida as implicações das paralizações de eventos para o setor e que todas as programações culturais teriam que acontecer em formato virtual e/ou on line, é possível citar dentre estes: Sesc ConVida promovido pelo Serviço Social do Comércio SESC, Festival UP, Prêmio Ibermúsicas, Prêmio Funarte Respirarte, dentre outros em nível nacional.

A partir da concepção de política de arena, Klaus Frey (2000) ao parafrasear Lowi (1972) apresenta que "as reações e expectativas das pessoas afetadas por medidas políticas têm um efeito antecipativo para o processo político de decisão e de implementação" (p.223). Os resultados a partir desses aspectos, segundo o autor se tornariam decisivos para a configuração do processo político como um todo. Deve-se conceber que a chamada política de arena teria relação direta com os conflitos e consensos, ou seja, as tensões, dentro dos diferentes espaços de política que obedeceriam às particularidades de seus respectivos caráteres: distributivo, redistributivo, regulatório ou constitutivo ${ }^{13}$. Ainda

12 Lei Aldir Blanc disponível pelo link <https://www.in.gov.br/en/web/dou/-/lei-n-14.017-de-29-de-junho-de-2020-264166628> Acesso em 06/10/2020.

${ }^{13}$ Para maior aprofundamento do caráter dos espaços políticos ler Frey (2000) em referências. 
conforme o autor existiria uma relação interna entre a percepção dos conteúdos da política por parte das pessoas afetadas e a estrutura da arena política (ibidem, p. 226).

É válido considerar que os processos de elaboração e implementação das políticas públicas de modo geral podem sofrer mudanças bruscas requerendo pronta reorganização devido ao dinamismo causado por grandes transformações sociais, pode-se citar como exemplo as ocasionadas pela COVID-19. Neste sentido:

Um fato pode ser percebido, pela primeira vez, como um problema político por grupos sociais isolados, mas também por políticos, grupos de políticos ou pela administração pública. Frequentemente, são a mídia e outras formas da comunicação política e social que contribuem para que seja atribuída relevância política a um problema peculiar. (FREY, 2000, p. 227).

Justifica-se, portanto, a necessidade da análise dialógica a partir do material divulgado pela imprensa local, uma vez que percebida a importância política de um determinado problema é que seriam adotadas medidas de ação por parte da política administrativa. Nesse caso, as instâncias de poder estruturadas via instituições políticas, de certo modo, seriam um reflexo das necessidades individuais ou sociais com "padrões regularizados de interação, conhecidos, praticados e em geral reconhecidos e aceitos pelos atores sociais, se bem que não necessariamente por eles aprovados" (ibidem: p. 231 -232). São relações de poder com forte potencial decisivo para o processo político e consequentemente para os resultados advindos deste.

Ademais, deve-se ressaltar que as identidades que coexistem dentro do referido campo são aspectos significativos que influem sobre os comportamentos e decisões dos agentes sociais com consequências nas relações que ali ocorrem no intuito de que as políticas adotadas possam atender as complexidades dos problemas apresentados de modo satisfatório.

As políticas públicas são programas e ações planejadas que visam assegurar direitos previstos pela Constituição e o bem estar social, pois implicam na vida de todas as pessoas que compõem uma sociedade. Neste sentido, é válido apontar as lacunas e fragilidades das políticas públicas emergenciais, ao se prender a burocracias administrativas demorando-se na efetiva prestação de auxílio ao profissional da arte e aos cidadãos como um todo, com significativa demora na tomada de decisões. Acentuado em certos casos a indiferença e a falta de sensibilidade e de estratégia de gestores culturais locais ao lidar com questões que afetam de forma significativa a vida dos profissionais da cultura em Manaus diante de uma situação sem precedentes e que requeria pronta mobilização.

Outra questão a se apontar refere-se à fiscalização das medidas de distanciamento físico, na tentativa de decrescer a disseminação da doença, até os impactos das medidas realizadas pelas instâncias de poder nas liberdades individuais das pessoas. Nesta perspectiva deve-se considerar:

(...) de um lado, vamos ter uma concepção da liberdade que é uma concepção jurídica - todo indivíduo detém originalmente certa liberdade da qual cederá ou não certa parte - e, de outro, a liberdade não vai ser concebida como exercício de certo número de direitos fundamentais, ela vai ser percebida simplesmente como a independência dos governados em relação aos governantes. Temos portanto duas concepções absolutamente heterogêneas da liberdade, uma concebida a partir dos direitos do homem, a outra percebida a partir da independência dos governados. (FOUCAULT, 2008, p.57).

Em meio à pandemia e todo empenho dos profissionais de saúde para conter o avanço da doença, uma parte da população assumindo uma postura negacionista/ conspiracionista se recusou a atender as recomendações sanitárias de isolamento social e de higiene como o uso de máscaras de pano ou ci- 
rúrgicas, parte delas movidas pela falta de perspectiva e demasiada demora do auxílio emergencial, e/ou pela alienação e "fake news" espalhadas via redes sociais.

[...] o interesse a cujo princípio a razão governamental deve obedecer são interesses, é um jogo complexo entre os interesses individuais e coletivos, a utilidade social e o benefício econômico, entre o equilíbrio do mercado e o regime do poder público, é um jogo complexo entre direitos fundamentais e independência dos governados. O governo, em todo caso o governo nessa nova razão governamental, é algo que manipula interesses. (FOUCAULT, 2008, p.61).

Em um primeiro momento, levada pelo excesso de informação em muitos casos de fontes duvidosas a respeito de uma nova doença de alcance mundial, a população local se mostrou descrente da gravidade e letalidade da COVID-19. Tal situação se acentuou evidenciando o número expressivo de mortes, além da crise no sistema de saúde e funerário da cidade amplamente noticiado em nível mundial.

\section{A importância da Música e do profissional da área em época de isolamento social}

A música, bem como a arte, mostra-se como algo profundamente necessário para a qualidade de vida no período de isolamento social, mesmo que fosse por meio de uma experiência mediada pela tecnologia, o que torna evidente a sua importância para a vida humana. Neste sentido, Blacking (2007) apresenta uma significativa questão para se refletir a respeito da experiência musical:

O "objeto artístico" em si não é arte nem não-arte: torna-se um ou outro somente pelas atitudes e sentimentos que os seres humanos lhe dirigem. A arte vive em homens e mulheres, sendo trazida a público por processos especiais de interação. (BLACKING, 2007, p. 202).

Assim sendo, para além das razões e/ou motivações de cunho financeiro ressalta-se a relevância da Música, bem como da Arte, na amenização das complexidades psicológicas dos seres humanos em período de isolamento, luto e incertezas com impactos na qualidade de vida e na sensação de bem-estar social. "Devemos também levar em conta as diferentes maneiras pelas quais os indivíduos e os grupos sociais produzem sentido daquilo que eles ou qualquer outro considera como 'música"' (Ibidem: p.203). O novo modo de interação que se impôs como modus operandi provisório, abarcando home studios e toda uma enorme diversidade de aparatos tecnológicos, foi absorvido significativamente pelos processos de criação e produção musical no referido campo.

Ainda assim, outra questão veio à tona, os artistas que não possuem familiaridades com a tecnologia ou sequer acesso satisfatório a ela enfrentam, de forma expressiva, dificuldades ainda maiores e se viram diante da impossibilidade de viabilizar seus trabalhos ou de terem que parar seus projetos temporariamente recorrendo a redes de apoio pontuais por meio de coletivos e movimentos sociais na cidade. Tais acontecimentos evidenciam as desigualdades de classe dentro do campo. O que antes da pandemia já tinha obstáculos intrínsecos se agravou com a chegada dela.

Todavia, deve-se ressaltar ainda a resistência feminina na música manauara que, apesar das adversidades e pressões em diferentes âmbitos da vida, agravadas em razão da pandemia, tem usado a seu favor as redes sociais e lançado suas músicas e videoclipes via internet e/ou pelas plataformas digitais, utilizando-se de gravações e projetos, em certos casos, viabilizados por editais anteriores a chegada do novo coronavírus, em outros por meio de recursos próprios e independentes, produzidos de modo parcial ou totalmente remotos, dentro das respectivas possibilidades; mobilizando o público com a abordagem de temáticas pontuais, tais como: relações abusivas, que em certos casos foram acentuadas a partir de convi- 


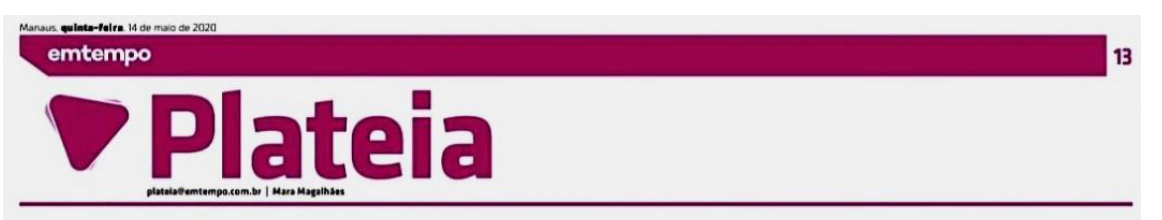

\section{Criações da quarentena}
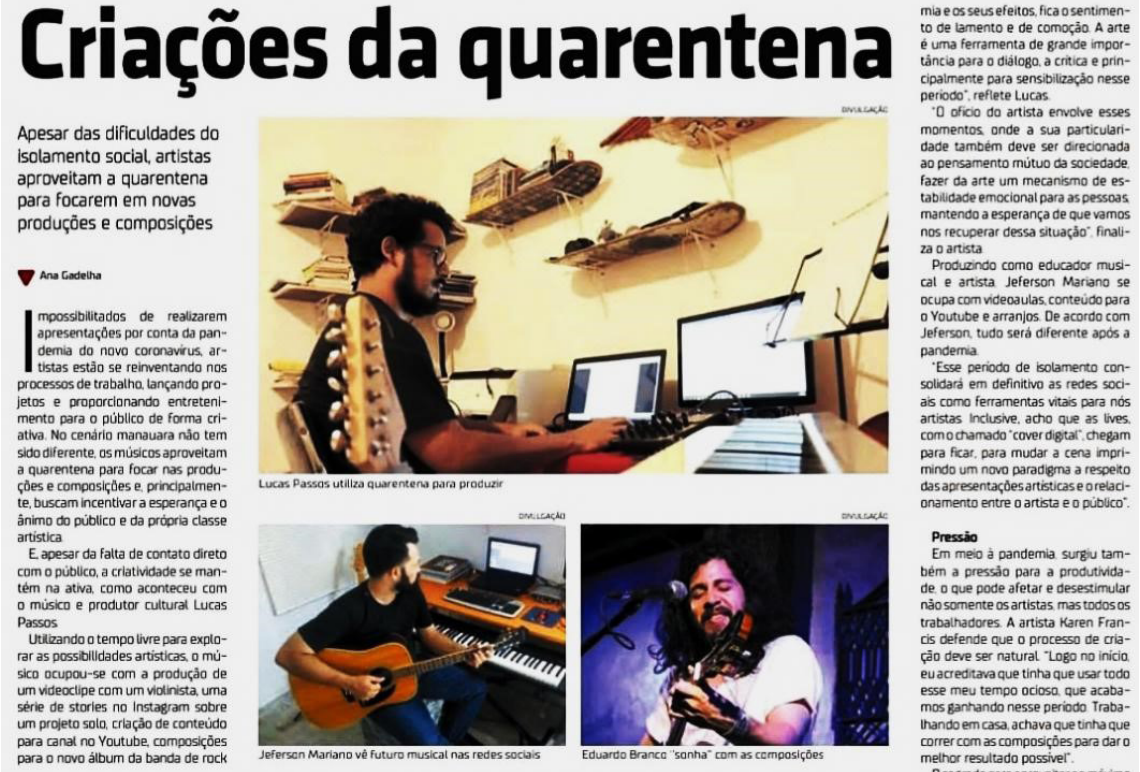
táncia para o dialogo. a critica e e prin-
cipalimente para sensibizaço nesse periodo: reflete Lucas
- 0 oficio do artista en momentos onde a suav particularsi-
dade tamberm deve ser direcionada

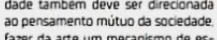

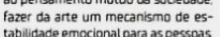
tabildade emocional para as pessoas
mantenco a esperança de que varmos

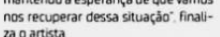
za o arista
Provinando como educador mus-

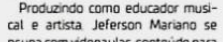

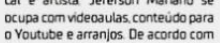
o Voutube earranios De acordo com
Jeferson tudo será diferente apos a pandermia
Esse periodo de kolamento con-
solidard em defintivo as redes soci-

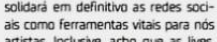
artistas Inchusive, avcho que as ives. para ficar, para mudar a cena impri-

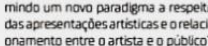

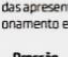
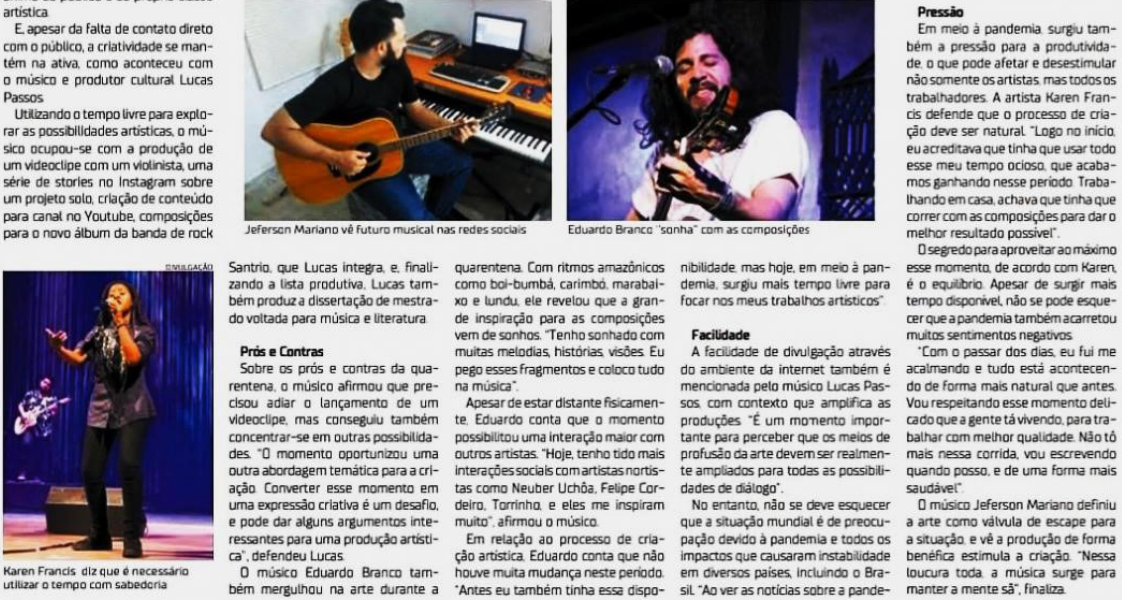
bém a presssio para a procuntividade o que pode afetar e desestimular

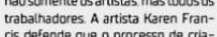
cis defende que o processo de cia-
çä deve ser natural "Logo no inicia. euarediara que tinha que usar tod

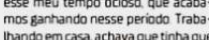
inandoem cassa achava que tinha que
correr com as composichees para dar

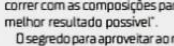
Osegredopara appovertar aomáximo éo equilbrio Apesar de surar mas cer que a a andemia tambémacarreto
multos sentimentos negativos multos sentmentos negatvos
"Como o passar dos dias eu fium acamando e tudo está acontecende forma mais natural que antes cauco que a gentete távivendo. paratrabahar com melhor qualidade Náo tó
más nessa corrida, vou escrevendo quadiver: 0.0 misco Jeferson Mariano definiu
a arte como vilvula de escape para a struagho e véa producsóde derma Ducura toda a música surge para

Figura 5 - Fonte: Jornal Em tempo. Caderno: Plateia. GADELHA, Ana. Título: “Criações da Quarentena”. Data: 14 de maio de 2020. Acesso em 04/10/2020.

vência forçada no contexto pandêmico, solidão da mulher negra, sustentabilidade ou até mesmo sobre o próprio trabalho autoral, dentre outras questões de forte impacto na vida social.

Deste modo, pode-se destacar, por exemplo, os trabalhos que artistas como Elisa Maia, Kely Guimarães, Ellen Fernandes, Anne Jezini, Nara da Mata, Karen Francis, Gabi Farias e Mady (da banda Mady e seus namorados) têm lançado e/ou produzido ao longo do período pandêmico e como essas produções musicais têm contribuído não só como entretenimento, mas também para o debate referente às questões que vão de relações de gênero à preservação do meio ambiente, além de movimentar a produção musical local em tempos de distanciamento físico.

Para entender tanto uma tradição musical quanto as contribuições que compositores individuais dão a ela, um sistema musical deve ser compreendido como um dos diferentes quadros de símbolos pelos quais as pessoas aprendem a produzir um sentido público de seus sentimentos e da vida social. (BLACKING, 2007, p. 205).

Nos grupos e fóruns de discussão relacionados à área cultural tem-se discutido além de tais questões, também a respeito do cuidado com os artistas e profissionais deste segmento como um todo. Pois se a Música tem atenuado os problemas referentes às questões do luto, da dor, do distanciamento físico para as 
pessoas de modo geral, no que se refere ao entretenimento e bem estar, faz-se imprescindível refletir sobre o trabalho artístico em si e sobre o próprio artista tendo que repensar seu processo criativo e composicional diante das adversidades e pressões impostas pela pandemia.

Neste sentido, os rendimentos provindos de direitos autorais têm suavizado em parte as necessidades financeiras de compositores associados às sociedades arrecadadoras vinculadas ao ECAD e isso tem relação com o aumento do uso de plataformas de streamings e aplicativos de música. Entretanto, não foram poucos os projetos de leis propostos em esfera federal com o intuito de ludibriar e atacar os direitos dessa classe e profissionais deste segmento. Além disso, deve-se ponderar que no campo musical em Manaus o número de compositores filiados às associações arrecadadoras ainda é ínfimo e, portanto, esse tipo de rendimento tem pouco impacto para a maior parte dos compositores/artistas que compõem esse campo, evidenciando a carência de conhecimentos de cunho empresarial fundamentais no exercício dessa profissão.

De modo geral, os profissionais da música em Manaus têm buscado se reinventar na produção de seus projetos como tentativa ainda incerta de não parar totalmente e dar prosseguimento às suas carreiras. Diante da impossibilidade de trabalhar da forma que se sabe, a COVID-19 além de trazer sentimentos contraditórios, ressaltou a fragilidade do trabalho artístico, no sentido da ausência de direitos trabalhistas, pejotização e exploração profissional, teria ainda a exposição a esse novo componente desconhecido, a doença em si que já levou a óbito vários e 'inumeráveis' artistas e profissionais locais, dentre eles, o músico Robson Lopes (Binho), o compositor Emerson Maia e o cantor Klinger Araújo.

Entretanto, mesmo diante do luto e da dor, a solidariedade e a empatia são aspectos que têm permeado o trabalho artístico no contexto pandêmico, evidenciando a importância da coletividade como forma de resistência e (re) existência diante da letalidade de uma doença pouco conhecida e do poder das instâncias governamentais que tentam se impor em diferentes direções, mas que na prática suas estratégias pouco contemplam satisfatoriamente as complexidades do trabalho nesse campo em meio a nova realidade e mesmo assim, só o tem feito a partir da pressão das reivindicações coletivas.

\section{Considerações}

Resistir às adversidades pode até ser algo que artistas e profissionais da cultura estejam acostumados a lidar, entretanto, o contexto social imposto pela pandemia do novo coronavírus se apresentou como uma situação sem precedentes na história local recente, assim como na mundial. As questões apresentadas neste artigo buscaram evidenciar de forma crítica, a partir de uma perspectiva sócio antropológica as relações de poder no campo musical em Manaus. Contextualizando-as com as matérias jornalísticas vinculadas nos principais meios de comunicação da cidade e embasando-as pela literatura da Sociologia e Antropologia visando um entendimento dos acontecimentos que têm afetado os profissionais da música especificamente no referido campo.

Ressaltou-se a busca por novas concepções de produção musical por parte de artistas em geral na tentativa de prover suas subsistências e dar novo sentido às suas existências, com reflexos em seus respectivos processos composicionais e nas músicas que produzem. Neste estudo, buscou-se explorar aspectos relacionados às instâncias que exercem o poder, políticas públicas emergenciais para a cultura e suas implicações nas relações sociais que ocorrem no campo musical local. Visto que diante de uma situação de pandemia seja de interesse de toda a humanidade priorizar a saúde e a preservação da vida humana. Assim sendo, as medidas sanitárias recomendadas pela Organização Mundial da Saúde - OMS são fundamentais.

As novas formas de produzir música, mediadas pela tecnologia, mesmo que de modo remoto, evidenciam que a capacidade humana de se reinventar diante de situações extremas é algo louvável e curioso. As possibilidades se renovam e ao mesmo tempo se instiga a buscar novos meios de expressões artísticas. Ser artista em condições 
habituais prescinde saber lidar com incertezas em vários âmbitos, neste sentido, o contexto pandêmico impôs novas condições que ainda estão sendo experimentadas implicando termos novos para o exercício desse trabalho.

As políticas públicas emergenciais elaboradas sob esta nova realidade evidenciam a importância da pressão popular e coletiva na reinvindicação de suas próprias demandas. As relações sociais nas quais os seres humanos estão envolvidos são uma fonte inesgotável de conhecimentos na busca por um entendimento mínimo, que seja, sobre os contextos sociais e suas implicações na vida humana. Deve-se ressaltar que, a música como manifestação da arte em si tem forte potencial político, principalmente num momento político brasileiro no qual não se prioriza a arte e as pluralidades culturais. Nesse sentido, a arte é dotada e adotada como forma de resistência e de (re) existência nas relações de poder e no espaço social e político no qual se situa também o campo musical.

\section{Referências}

BLACKING, John. Música, cultura e experiência. Tradução: André-Kees de Moraes Schouten. Revisão Técnica: Daniela do Amaral Alfonsi, Paula Wolthers, Lorena Pires e Thaís Chang Waldman. Cadernos de campo, São Paulo, n. 16, p. 1-304, 2007.

BOURDIEU, Pierre. A distinção: crítica social do julgamento. Tradução: Daniela Kern; Guilherme J.F. Teixeira. São Paulo: Edusp; Porto Alegre: Zouk, 2007.

BRASIL. Decreto Legislativo no 6, de 20 de março de 2020. Disponível pelo link <http://www.planalto.gov. br/ccivil_03/Portaria/DLG6-2020.htm> Acesso em 05/10/2020.

BRASIL. Lei no 14.017, de 29 de junho de 2020 (Lei Aldir Blanc). Disponível pelo link <http://www.planalto.gov.br/ccivil_03/_ato2019-2022/2020/lei/L14017.htm> Acesso em 05/10/2020.

CAVALCANTI, Vinícius Manrique. Bourdieu leitor de Weber, pistas para uma gênese do conceito de campo. Revista Cadernos de Ciências Sociais da UFRPE. Dezembro, 2012.

FREY, Klaus. Políticas Públicas: um debate conceitual e reflexões referentes à prática da análise de políticas públicas no Brasil. Artigo publicado. Revista Planejamento e Políticas Públicas. No 21, Jun de 2000.

FOUCAULT, Michel. Nascimento da Biopolítica. Curso dado no Collège de France (1978-1979). Tradução de Eduardo Brandão. Edição de Michel Senellart dirigida por François Ewald e Alessandro Fontana. Editora: Martins Fontes, São Paulo, 2008. (Coleção Tópicos).

FUNDAÇÃO DE VIGILÂNCIA E SAÚDE DO AMAZONAS - FVS/AM. Disponível no link < http:// www.fvs.am.gov.br/noticias_view/3833> Acesso em 09/04/2020.

noticias_view/3862>. Acesso em 05/10/2020.

Disponível pelo link<http://www.fvs.am.gov.br/

Disponível pelo link <http://www.fvs.am.gov.br/

noticias_view/4196>. Acesso em 05/10/2020.

Disponível pelo link <http://www.fvs.am.gov.

br/media/publicacao/05_10_20_BOLETIM_DI\%C3\%81RIO_DE_CASOS_COVID-19.pdf> Acesso em $06 / 10 / 2020$. 
Matérias de Jornais

ABREU, Wallace; CASTRO, Álisson. Operação da PF atinge Governo Wilson Lima. Jornal: D24am, Caderno Política. Disponível pelo link <https://d24am.com/politica/operacao-da-pf-atinge-governo-wilson-lima/>. Acesso em 13/10/2020.

ASSIMEN, Hanne. Lives solidárias são realizadas em prol de artistas amazonenses. Matéria do Jornal A crítica de 09/04/2020. Caderno Bem viver. Página BV1, também disponível no link <https://www.acritica. $\mathrm{com} /$ channels/entretenimento/news/lives-solidarias-sao-realizadas-em-prol-de-artistas-amazonenses > Acesso em 09/04/2020.

BORGES, Patrícia. No Amazonas, movimento exige políticas públicas ao setor cultural durante pandemia. Portal Amazônia. Data 02/04/2020 disponível pelo link <https://portalamazonia.com/cultura/no-amazonas-movimento-exige-politicas-publicas-ao-setor-cultural-durante-pandemia> Acesso em 10/04/2020.

GADELHA, Ana. Título: Criações da Quarentena. Jornal Em tempo. Caderno: Plateia. Página 13. Data: 14 de maio de 2020. Acesso em 04/10/2020. Acervo pessoal.

LEVENTI, Anamaria. Amazonas tem 804 casos do novo coronavírus, divulga FVS-AM nesta quarta. Matéria do Jornal D24am de 09/04/2020. Disponível no link <https://d24am.com/coronavirus-no-amazonas/ amazonas-tem-804-casos-do-novo-coronavirus-divulga-fvs-am-nesta-quarta > Acesso em 09/04/2020.

MELO, Tiago. Título: Planos musicais: artistas do setor reinventam projetos. Jornal A crítica. Caderno: Bem viver. Página BV1, Data: 22 de abril de 2020. Acesso em 04/10/2020.

Portal da Secretaria de Estado de Cultura Economia Criativa do Amazonas - SEC/AM. Disponível no link $<$ https://cultura.am.gov.br/portal/lives-solidarias-arrecadam-doacoes-para-artistas-no-amazonas $>$ Acesso em $09 / 04 / 2020$.

Portal Amazônia. Redação. Matéria disponível pelo link <https://portalamazonia.com/cultura/musica/musico-realiza-live-solidaria-para-ajudar-colegas-prejudicados-com-o-coronavirus?fbclid=IwAR0Z7UO_ lhXqU3w27-33IDV-som_EwRHG_Riz-YXaMOdEZKsY6Pa2FiKaAw> Acesso em 18/04/2020.

Portal da Secretaria de Estado de Cultura e Economia Criativa - SEC/AM. Disponível pelo link < https:// cultura.am.gov.br/portal/mais-de-4-mil-artistas-e-profissionais-se-cadastram-em-mapeamento-do-governo-do-amazonas/> Acesso em 06/10/2020.

Recebido em 18/10/2020

Aceito em 23/11/2020 